\title{
An epidemiological study on Depression and related factors among Geriatrics in a tertiary care Hospital.
}

\author{
Dr Siddhartha Sankar Saha ${ }^{1}$, Dr Pradeep Kumar Saha ${ }^{1}$ \\ ${ }^{I}$ Department of Psychiatry, Institute of Psychiatry, Kolkata, India
}

\begin{abstract}
Depression in old age is associated with genetic susceptibility, chronic disease and disability, pain, frustration with limitations in activities of daily living. The present hospital based cross sectional study was undertaken on 306 patients selected by systemic consecutive sampling from Geriatric O.P.D of Institute of Psychiatry, Kolkata to find out the prevalence of depression and associated factors among geriatric patients. $65.3 \%$ of the study population had depression (mild-36.2\%, severe-29.1\%) and the association of this depression with age $(p<.001)$, gender $(p<.001)$, residence $(p=.027)$, marital status $(p=.004)$, education $(p<.001)$, occupation ( $p<.001)$, family type $(p<.001)$ and economic dependency $(p=.002)$, living condition $(p<.001)$ was statistically significant. Social support group, local clubs and respective families should address the issue of depression among elderly. Family counselling for old age care, creation of a viable family and social environment will go a long way to improve the mental health of the elderly.
\end{abstract}

Key Words: geriatric, depression, mental health, family

\section{Introduction}

Ageing has not only social but also economic, political and health-related implications. ${ }^{1}$ The population aged 60 years and above will grow from 77 million in 2001(7.4\%) to 150 million (14.41\%) in 2020 and 2050 it will touch 300 million being $2^{\text {nd }}$ largest geriatric population in the world.. ${ }^{2}$ Geriatric populations comprises $7.2 \%$ of total population of West Bengal. Age is an important determinant of mental illness. The overall prevalence of mental and behavioural disorders tends to increase with age due to the normal ageing of the brain, deteriorating physical health and cerebral pathology. ${ }^{3}$ Lack of family support and restricted personal autonomy are other important contributing factors .Geriatrics are more prone to infections and injuries and they have increased risk of disease, disability and death. Mental health is an important concern and depression accounts for the greatest burden among them, expected to become the leading cause of disability by year 2020 closely following ischemic heart disease. ${ }^{4}$ Globally, prevalence of depression in geriatric population varies from $10 \%$ to $20 \%$, while in India; it is even higher varying from $13 \%$ to $25 \% .^{5}$ Depression in old age is associated with genetic susceptibility, chronic disease and disability, pain, frustration with limitations in activities of daily living, personality trait (dependent, anxious or avoidant), adverse life events and lack of adequate social support. In a hospital-based study. ${ }^{6}$ it was found that nearly $52.5 \%$ of the patients with chronic medical illness suffer from psychiatric illness, depression being the most common. Uwakwe et $\mathrm{al}^{7}$ evaluated all the patients aged more than 60 years, who were admitted in psychiatric wards in a teaching hospital and observed that $45.3 \%$ of the patients had psychiatric illness, with depression being the commonest followed by organic disorders, adjustment disorder, and generalized anxiety disorder. Only $2.8 \%$ of the mental disorders could be recognized by the physicians. This reflects the need for psychological assessment among the geriatric patients. With this background, we have conducted this study with the following objectives:

1. To find out the prevalence of depression among elderly patients attending geriatric O.P.D of Institute of Psychiatry, Kolkata.

2. To assess the related socio demographic factors affecting depression among geriatric patients.

\section{Methodology}

An observational, cross- sectional study was conducted among the patients aged 65 years and above attending Geriatric OPD of Institute of Psychiatry, Kolkata from January 2011 to July 2011. Informed verbal consent was taken from each patient; anonymity and confidentiality were ensured. Patients those who were seriously ill and unwilling to give consent excluded from the study. A predesigned pre-tested schedule (for background information) and Geriatric Depression Scale GDS- $15^{8}$ (for assessment of Depression) were used as study tools. The GDS, developed by TL Brink et al is a 15 item self-rated scale used to evaluate depression in elderly. The GDS has demonstrated very good internal consistency (alpha 0.94 ) and split half reliability of 0.94 . Stability of GDS is also very good with a test-retest correlation of 0.85 over one week. GDS score $0-4$ considered as normal. GDS score 5-9 and 10-15 considered as mild and severe depression respectively. Interview time took approximately 10-15 minutes. 15-16 patients were interviewed per day by systematic consecutive sampling. Every $3^{\text {rd }}$ patient was interviewed. If the patient was not willing or interviewed earlier 
then the next patient fulfilling the inclusion criteria was selected. So during the study period 314 patients were interviewed. Due to incompleteness of response by 8 patients, finally 306 schedules were used for analysis. Data was tabulated in Microsoft Excel 2010 spread sheet and were analysed by appropriate statistical methods in SPSS version 16.

\section{Results}

Maximum study population (69\%) belonged to 60-69 years age group. Male respondents were $54.2 \%$ and urban residents were 76.5\%.Major physical morbidities observed in the study population were Hypertension (64.2\%) Osteoarthritis(62.4\%),Low Back Pain (55.7\%) Visual Impairment (54.2\%),Diabetes (46.4\%). Majority of study population ( $81 \%$ ) belongs to Hindu religion. Among the study population, $24 \%$ were illiterate \& only $12 \%$ having higher education. Majority of study population (64\%) were married. $39 \%$ \& $26 \%$ of study population are homemakers and retired respectively. About $22 \% \& 36 \%$ of study population living with spouse, unmarried and spouse, married children respectively while 12\% (19) living alone. About 37\% of study population have PCI< Rs 547. Majority of study population (77\%) were residing in pucca house. Only $44 \%$ of study populations were economically fully independent. Nearly $28 \%$ of the study populations were addicted to tobacco smoking. Among the study population, $36 \%$ were lonely and had other member's problem. $65.3 \%$ of the study population had depression (figure 1) (mild-36.2\%, severe-29.1\%) and the association of this depression with age $(p<0.001)$, gender $(p<0.001)$, residence $(p=0.027)$, marital status $(p<0.05)$ (table4), education ( $\mathrm{p}<0.001)$, occupation $(\mathrm{p}<0.001)$, family type $(\mathrm{p}<0.001)$ and economic dependency (table 1$)(\mathrm{p}<0.05)$, living condition $(\mathrm{p}<0.01)$ (table 2$)$ was statistically significant.

\section{Discussion}

This cross-sectional study was conducted to analyze the socio-demographic profile and prevalence of depression among geriatric patients of a teaching hospital setting. The initial study sample was 314 patients out of which, 8 had to be excluded due to incompleteness of the proforma. The final study sample was 306 . Out of 306 patients, $200(65 \%)$ had depression. Other studies conducted in different parts of India highlighted the prevalence of depression among geriatrics varied from $31.2 \%$ to $81.02 \%{ }^{9,10,11,13}$ This difference may be due to different study setting and difference in guideline for consideration of geriatric population. In our study $54 \%$ were male and $46 \%$ were female. Mean age was 66.18 years with SD \pm 5.56 years. A study conducted at Government Medical College Amritsar showed that among the study population 64\% were men and $36 \%$ were women. ${ }^{9}$ Study in tertiary care hospital of Delhi showed that the age of the patients ranged from 60 to 88 years with the mean age being 64.5 years and there were $122(61 \%)$ males and $78(39 \%)$ females. ${ }^{10}$ Study from Aga Khan university of Karachi showed $78 \%$ were male and mean age was 69 years. ${ }^{12}$ This variation was due to different socio-economic status of the study population. The present study highlighted that age $(p<0.001)$, gender $(\mathrm{p}<0.001)$, residence $(\mathrm{p}=0.027)$, marital status $(\mathrm{p}<0.05)$, education $(\mathrm{p}<0.001)$, occupation $(\mathrm{p}<0.001)$, family type $(\mathrm{p}<0.001)$ and economic dependency $(\mathrm{p}<0.05)$, living condition $(\mathrm{p}<0.01)$ were the major predictors of depression among the study population. Significant association between age and depression was found by Sood et.al. ${ }^{9}$ Persons from nuclear family had more depressive symptoms. ${ }^{11}$ Study from Aga Khan University Hospital Karachi depicted that females were found to be 2.6 times more likely to suffer from depression compared to males $(\mathrm{p}<0.001)$. Married people were less likely to suffer from depression compared to those who did not marry or who were separated or widowed $(\mathrm{p}<0.001)$. The subjects living in a nuclear family system were more likely to suffer from depression than those living in a joint family system. Other factors that showed a significant association with depression in the subjects included being uneducated $(p=0.03)$, living alone $(\mathrm{p}<0.001)$, being childless $(\mathrm{p}<0.001)$, and being unemployed $(\mathrm{p}<0.001) .{ }^{12}$ A study conducted by $\mathrm{V}$ Jariwala in Surat City showed that illiterates have a much lower rate of depression (26.6\%) than literates $(44 \%) .{ }^{13}$ Study conducted by Grover S et. al. explored that depression was more common in women, younger subjects, in subjects from poor economic background, Muslims, those who were divorced or widowed, those residing in nuclear families and urban resident. ${ }^{14}$ These differences could be due to the difference in the study population and different study setting. Decreased prevalence of depression among the patients from joint families could be due to a better emotional and social support that a person gets in a joint family, compared to a nuclear family. Various factors like changing social circumstances, lifestyle changes could be responsible for this. This also emphasizes that awareness and support have to be improved at social and community level. Adequate training of medical professionals was needed to recognize and refer the patients for a better geriatric care.

\section{Conclusion}

Health education should be given to geriatric people regarding regular physical exercise, nutrition and medical check up for early detection of disease. Strengthening of medical services exclusively for elderly population was needed at CHCs and tertiary care hospital. The service providers should be given special training 
in management of geriatric health problems. The elderly people themselves should be encouraged to form old age club and participate in various cultural programme to improve their quality of life. Social support group, local clubs and respective families should address the issue of depression among elderly. National programme for health care of elderly (NPHCE) has started in 2010 and pioneer NGOs like Help Age India organising screening camps and mobile clinical units in Rural and difficult to approach area.

\section{Tables and Charts}

Fig1: Bar diagram showing prevalence of depression among the study population $\quad(n=306)$

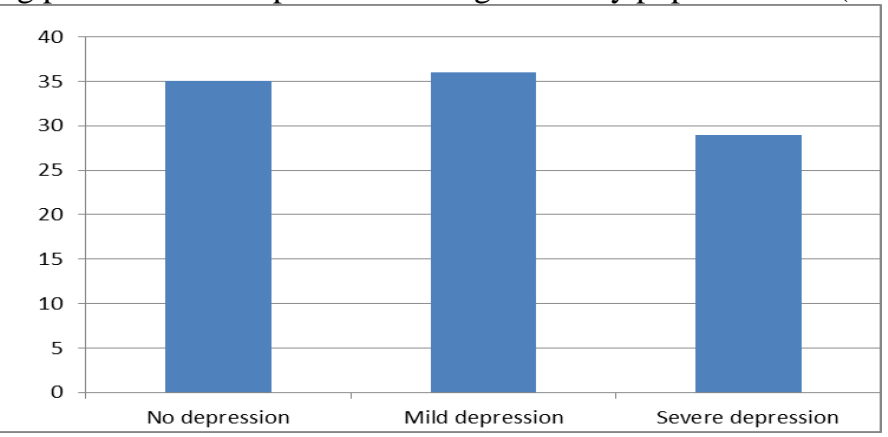

Table 1: Relationship between economic dependency of the study population with Depression

$$
(\mathrm{n}=306)
$$

\begin{tabular}{|l|c|c|c|c|}
\hline \multirow{2}{*}{$\begin{array}{l}\text { Economic } \\
\text { dependency }\end{array}$} & \multicolumn{3}{|c|}{ GDS Scale (0-15) } & \multirow{2}{*}{ Significance } \\
\cline { 2 - 4 } & $\begin{array}{c}\text { No depression } \\
(0-4)\end{array}$ & $\begin{array}{c}\text { Mild depression } \\
(5-9)\end{array}$ & $\begin{array}{c}\text { Severe depression } \\
(10-15)\end{array}$ & \\
\hline Fully dependent & 34 & 62 & 54 & $\chi^{2}=13$ \\
Partially & & 10 & 6 & $\mathrm{df}=4$ \\
dependent & 6 & 38 & 30 & \\
Independent & 66 & 110 & 90 & \\
Total & 106 & & \\
\hline
\end{tabular}

Table 2: Relationship between living condition of the study population with Depression $(\mathrm{n}=306)$

\begin{tabular}{|l|c|c|c|c|}
\hline \multirow{2}{*}{ Living With } & \multicolumn{3}{|c|}{ GDS Scale $(0-15)$} & \multirow{2}{*}{ Significance } \\
\cline { 2 - 4 } & $\begin{array}{c}\text { No depression } \\
(0-4)\end{array}$ & $\begin{array}{c}\text { Mild depression } \\
(5-9)\end{array}$ & $\begin{array}{c}\text { Severe depression } \\
(10-15)\end{array}$ & \\
\hline Alone & 0 & 10 & 28 & \\
With Spouse & 4 & 4 & 16 & \\
Spouse \& unmarried Children & 30 & 26 & 12 & \\
Spouse with married Children & 48 & 46 & 16 & $\chi^{2}=40.31$ \\
With unmarried Children & 8 & 12 & 4 & $\mathrm{df}=12$ \\
With married Children & 12 & 4 & 8 & \\
Others & 4 & 8 & 6 & \\
Total & 106 & 110 & 90 & \\
\hline
\end{tabular}

Table 3: Distribution of study population according to social problem $(n=306) *$

\begin{tabular}{|l|c|c|}
\hline Social Problem & Frequency & Percentage \\
\hline Loneliness & 74 & 24.2 \\
Destitution & 8 & 2.6 \\
Property problem & 28 & 9.1 \\
Other members problem & 60 & 19.6 \\
None & 162 & 52.0 \\
\hline
\end{tabular}

*Multiple responses

Table 4: Relationship between Marital Status of the study population with Depression $(\mathrm{n}=306)$

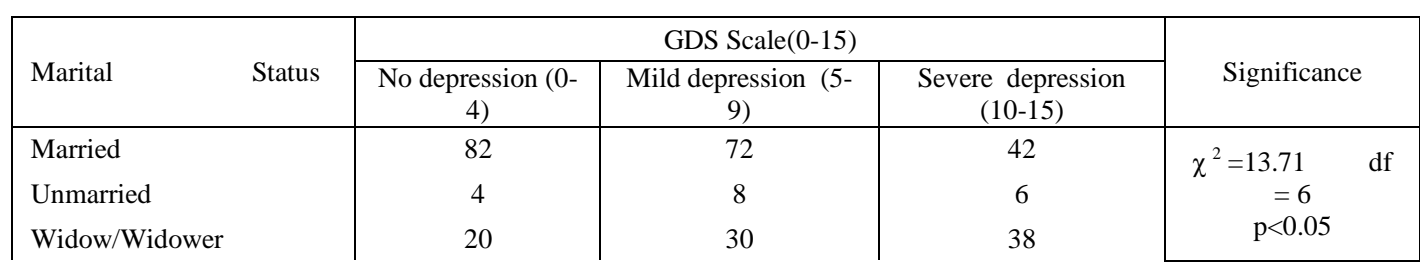


Husband absconded

Total

\section{0}

106
0

110
90

\section{References}

[1] Indian J Psychiatry. 2006 Jan-Mar; 48(1): 56-61.

[2] United Nations, World Demographic Estimate and Projections

[3] Ingle GK et al. Geriatric Health in India: Concerns and Solutions. Indian Journal of Community Medicine. 2008;33(4):214-218.

[4] Murray CJ and Lopez AD. Alternative Projections of Mortality and Disability by Cause 1990-2020: Global Burden of Disease Study. Lancet 1997;349:1498-504.

[5] Poongothai S, Pradeepa R, Ganesan A, Mohan V. Prevalence of depression in a large urban South Indian population - The Chennai Urban Rural Epidemiology Study (CURES-70). PloS One2009;4:E7185.

[6] Abhay K et al. Psychiatric disorders in medical inpatients. Indian J Psychiatry 2008;40:73-8

[7] Uwake R. Psychiatric morbidity in elderly patients admitted into non psychiatric wards in a teaching hospital in Nigeria. Int $\mathbf{J}$ Geriatr Psychiatry 2000;15:346-54

[8] Brink TL et al,Development and Validation of a Geriatric Depression Scale: A preliminary report.J Psychiatr Res,1982, 17(1): 3749

[9] Sood A, Singh P, Gargi DP. Psychiatric morbidity in non-psychiatric geriatric inpatients. Indian J Psychiatry. 2006;48(1):56 - 61

[10] Kalra S, Jhamb R, RuchiR.Profile of Medical and Psychological Disorders in the Elderly Persons attending a Tertiary Care Hospital in DelhiJIACM 2011; 12(1): 21-5

[11] Kumar KL, Kar S, Reddy PK. Psychiatric co-morbidity in geriatric inpatients. J Dr NTR Univ Health Sci 2012;1:81 - 5

[12] Taqui AM, Ahmed Itrat, WarisQidwai, ZeeshanQadri.Depression in the elderly: Does family system play a role? BMC Psychiatry 2007, 7:57

[13] VJariwala ,RK Bansal ,S Patel ,B Tamakuwala. A Study of depression among aged in Surat City. National Journal of Community Medicine 2010; 1:1

[14] Grover S, Dutt A, and Avasthi A: An overview of Indian research in depression Indian J Psychiatry. 2010; 52: 178-88. 